\title{
A genetic linkage study in Brazil identifies a new locus for persistent developmental stuttering on chromosome 10
}

\author{
C.E.F. Domingues ${ }^{1,2}$, C.M.C. Olivera ${ }^{3}$, B.V. Oliveira ${ }^{2}$, F.S. Juste ${ }^{4}$, \\ C.R.F. Andrade ${ }^{4}$, C.M. Giacheti ${ }^{3}$, D. Moretti-Ferreira ${ }^{2}$ and D. Drayna ${ }^{1}$ \\ ${ }^{1}$ National Institute on Deafness and other Communication Disorders, \\ National Institutes of Health, Rockville, MD, USA \\ ${ }^{2}$ Departamento de Genética, Instituto de Biociências de Botucatu, \\ Universidade Estadual Paulista "Júlio de Mesquita Filho", \\ Botucatu, SP, Brasil \\ ${ }^{3}$ Departamento de Fonoaudiologia, Centro de Estudos da Educação e da Saúde, \\ Universidade Estadual Paulista "Júlio de Mesquita Filho", \\ Marília, SP, Brasil \\ ${ }^{4}$ Departamento de Fonoaudiologia, Fisioterapia e Terapia Ocupacional, \\ Faculdade de Medicina da Universidade de São Paulo, \\ São Paulo, SP, Brasil
}

Corresponding author: D. Drayna

E-mail: drayna@nidcd.nih.gov

Genet. Mol. Res. 13 (1): 2094-2101 (2014)

Received July 29, 2013

Accepted February 19, 2014

Published March 24, 2014

DOI http://dx.doi.org/10.4238/2014.March.24.13

\begin{abstract}
Although twin, adoption, and family studies demonstrate that genetic factors are involved in the origins of stuttering, the mode of transmission of the disorder in families is not well defined and stuttering is considered a genetically complex trait. We performed a genomewide linkage scan in a group of 43 Brazilian families, each containing multiple cases of persistent developmental stuttering. Linkage analysis under a dominant model of inheritance generated significant evidence of linkage in two Brazilian families, with a combined maximum
\end{abstract}


single-point LOD score of 4.02 and a multipoint LOD score of 4.28 on chromosome 10q21. This demonstrated the presence of a novel variant gene at this locus that predisposes individuals to stuttering, which provides an opportunity to identify novel genetic mechanisms that underlie this disorder.

Key words: Stuttering; Linkage; Dominant; Chromosome 10q

\section{INTRODUCTION}

Although the etiology of developmental stuttering is not well understood, there is a consensus that genetic factors are involved, and studies of twins (Howie, 1981; Andrews et al., 1991; Felsenfeld et al., 2000; Ooki, 2005; Dworzynski et al., 2007; Fagnani et al., 2011; Rautakoski et al., 2012) and families (Kidd et al., 1978; Seider et al., 1983; Cox et al., 1984; Viswanath et al., 2004) have contributed to the substantial evidence for the role of inherited factors in the etiology of this disorder. Despite the extensive evidence for genetic factors, however, the exact mode of transmission in families is not well defined, and it is unlikely to be the same in all families and populations (Alm and Risberg, 2007). For example, a number of linkage loci have been identified in consanguineous families, particularly from Pakistan (Riaz et al., 2005; Raza et al., 2010, 2012), while studies in outbred families in the United States have not demonstrated linkage at these loci (Shugart et al., 2004; Suresh et al., 2006). The goal of this study was to identify genetic factors underlying persistent developmental stuttering in the Brazilian population, which displays a high degree of genetic admixture, and is thus quite different from the populations used for previous genetic studies of stuttering. Accordingly, we performed a genome-wide linkage scan in a group of Brazilian families, each containing multiple cases of persistent developmental stuttering.

\section{MATERIAL AND METHODS}

The study was approved by the respective institutional review boards (Research Ethics Committee of Botucatu Medical School, UNESP, Brazil, No. 3441/2010-CEP; National Committee for Ethics Research, No. 16349; National Institutes of Health, protocol No. 97-DC-0057), and written informed consent or assent, as appropriate according to the age of the subject, was obtained from all participants. Blood and recorded speech samples were collected from all available family members. A total of 43 unrelated Brazilian families were enrolled from São Paulo State, Brazil. The sample consisted of 312 individual participants, 131 of whom were diagnosed as affected with persistent developmental stuttering. Stuttering diagnosis was determined by at least two speech pathologists and was established based on self-expressive speech samples (Andrade et al., 2004) of at least 200 syllables elicited by visual stimuli (pictures) adapted for different age groups. Affected individuals were defined as those with a stuttering dysfluency rate of $3 \%$ and a score of 11 points or more from the Stuttering Severity Instrument, 3rd edition (SSI-3) (Riley, 1994), were age 6 years and older, had stuttered for at least 6 months, and had at least one additional affected family member. Exclusion criteria were: family history of genetic or non-genetic neurological disorders [e.g., dystonia, extra pyramidal disease, mental disorder, epilepsy, attention deficit hyperactivity 
disorder, psychiatric symptoms or conditions, oral communication impairment not compatible with age, conductive or neurosensory hearing loss, or other developmental conditions] that could generate errors in diagnosis. Genotyping was performed using the Illumina HumanLinkage-24 BeadChip that assayed 5913 single nucleotide polymorphisms (SNPs) in all 312 individuals. Samples from 26 Brazilian unaffected individuals were genotyped to estimate SNP allele frequencies in the Brazilian population. The quality of SNP genotypes was evaluated according to the manufacturer protocol using the Illumina ${ }^{\circledR}$ GenomeStudio V2009.2 software (analysis parameters: cluster separation, call frequency, AB R mean, AB $\mathrm{T}$ mean, Mendelian inheritance, heterozygote excess, minor allele frequencies; available at: $\mathrm{http} / / /$ www.illumina.com/Documents/products/technotes/technote_infinium_genotyping data analysis.pdf). Nine percent of SNPs failed to meet the recommended criteria and were excluded, leaving a total of 5379 SNPs analyzed for linkage.

Single-marker parametric linkage analysis was performed using SuperLink v1.6 (Hoffmann and Lindner, 2005) from the easyLINKAGE-Plus v5.08 package (available at: http://sourceforge.net/projects/easylinkage/) for SNP data. Confirmation of results from SNPs was done by genotyping microsatellite markers on chromosome 10 with standard fluorescent methods using an ABI 3730 XL capillary instrument and GeneMapper ${ }^{\circledR}$ v.4.0 (Applied Biosystems, USA), followed by MLINK analysis (Cottingham Jr. et al., 1993) and SUPERLINK online V1.5 (Fishelson and Geiger, 2002; Silberstein et al., 2006). SLINK was used to calculate simulated LOD scores using a single-marker power calculation with 1000 replicates (Ott, 1989). Microsatellite allele frequencies were estimated by genotyping 48 Brazilian normal control individuals. MERLIN (available at: http://www.sph.umich.edu/ csg/abecasis/Merlin/download/) was used to calculate most likely haplotypes (Abecasis et al., 2002), and HAPLOPAINTER (available at: http://sourceforge.net/projects/haplopainter/) was used to plot the pedigree with the haplotypes (Thiele and Nurnberg, 2005). Analysis was initially performed on both individual families and on the combined family set with the disease allele frequency set at 0.01 .

\section{RESULTS}

Analysis of the combined family set of 43 families under dominant, recessive, and additive models of inheritance failed to generate significant evidence of linkage. Analysis of individual families demonstrated suggestive evidence of linkage in two families (BRPD47 and BRPD50), while all other individual families displayed no significant evidence for linkage under any model of inheritance. Families BRPD47 and BRPD50 both showed evidence of linkage to SNP markers rs $158421(78.85 \mathrm{Mb})$ and rs1904764 (58.81 Mb) on chromosome $10 \mathrm{q}$. These markers generated LOD scores of 1.59 and 1.32, respectively, under a dominant model of inheritance, which was viewed as the most plausible model based on the segregation of stuttering in these two families. Subsequent analysis under recessive and additive models gave reduced scores in these families. Analysis of both families together under a dominant model (penetrance classes $0.01,0.99,0.99)$ produced positive LOD scores at multiple markers, including rs1268722 (LOD =3.11); rs77839 (LOD = 2.05); rs1917810 (LOD = 1.97); rs913034 $(\mathrm{LOD}=1.84)$, and rs1427209 $(\mathrm{LOD}=1.83)($ Table $1 \mathrm{~A}$ and $\mathrm{B})$.

Based on these results, we performed fine mapping using microsatellite markers that extended from markers D10S34 (48.38 Mb) to D10S535 (76.34 Mb) (Genome build 36/hg18). 
Analyses of these markers under a dominant model produced a maximum single-marker LOD score of 2.57 in BRPD47 at D10S1643, while the maximum score of 1.74 in BRPD50 was generated at multiple markers in this region, extending from D10S604 (44.84 Mb) to D10S2480 $(70.32 \mathrm{Mb})$. The analysis in the two families combined generated a pairwise LOD score of 4.02 at marker D10S220 (Table 1B). Multi-point analysis based on six microsatellite markers using the same inheritance model generated higher LOD scores. For BRPD47, an LOD score of 2.49 was obtained at D10S1790 (55.2 Mb), and the LOD score exceeded 2.4 across the region from D10S604 $(44.84 \mathrm{Mb})$ through D10S529 $(71.83 \mathrm{Mb})$. In BRPD50, a maximum score of 1.78 was generated, with a flat LOD score curve between D10S604 (44.84 Mb) and D10S1670 (68.87 Mb). Analysis of these two families combined generated a maximum LOD score of 4.28 at marker D10S1790 (Table 1C).

Table 1. Microsatellite linkage on chromosome 10q in families BRPD47 and 50. A. Marker map; B. and C. Single-marker and multipoint analysis results, respectively.

\begin{tabular}{|c|c|c|c|c|c|c|c|c|c|}
\hline \multicolumn{3}{|l|}{ A. } & \multirow{3}{*}{\multicolumn{3}{|c|}{$\begin{array}{l}\text { B. } \\
\frac{\text { Single-marker analysis }}{\text { LOD score }(\theta=0)} \\
\text { Family BRPD }\end{array}$}} & \multirow{5}{*}{$\begin{array}{l}\text { C. } \\
\text { Distance (cM) from } \\
\text { marker D10S604 } \\
\\
\quad-10\end{array}$} & \multirow{3}{*}{\multicolumn{3}{|c|}{$\begin{array}{c}\text { Multipoint analysis } \\
\text { Max. LOD score } \\
\text { Family BRPD }\end{array}$}} \\
\hline \multirow{5}{*}{ Marker ID } & \multirow{5}{*}{$\mathrm{cM}$} & \multirow{5}{*}{$\mathrm{Mb}$} & & & & & & & \\
\hline & & & & & & & & & \\
\hline & & & 47 & 50 & $47+50$ & & 47 & 50 & $47+50$ \\
\hline & & & & & & & 2.0565 & 1.4588 & 3.5177 \\
\hline & & & & & & -5 & 2.2339 & 1.618 & 3.8544 \\
\hline D10S604 & 66.5 & 44.84 & 1.8 & 1.74 & 3.54 & 0 & 2.4196 & 1.7863 & 4.2087 \\
\hline D10S225 & 70.06 & 48.03 & 2.22 & 1.15 & 3.37 & 1.865 & 2.4452 & 1.7843 & 4.2309 \\
\hline D10S1787 & 68.63 & 49.83 & 0.13 & 0.32 & 0.45 & & & & \\
\hline D10S1772 & 68.63 & 50.04 & 0.75 & 0.05 & 0.8 & & & & \\
\hline D10S1793 & 68.63 & 50.13 & 0.29 & -0.38 & -0.09 & & & & \\
\hline D10S1766 & 69.7 & 50.75 & 1.37 & 1.01 & 2.38 & & & & \\
\hline D10S196 & 70.23 & 52.14 & 2.18 & 1.15 & 3.32 & & & & \\
\hline D10S220 & 70.23 & 52.35 & 2.28 & 1.74 & 4.02 & 3.73 & 2.4731 & 1.7846 & 4.2577 \\
\hline D101220 & 70.23 & 52.68 & 1.2 & 1.73 & 2.93 & 6.4 & 2.4815 & 1.7863 & 4.2644 \\
\hline D10S568 & 71.83 & 53.72 & 2.27 & 0.28 & 2.55 & & & & \\
\hline D10S567 & 71.83 & 53.92 & 2.56 & 0.29 & 2.85 & & & & \\
\hline D10S539 & 72.9 & 55.06 & 0.72 & 1.74 & 2.46 & & & & \\
\hline D10S1790 & 75.57 & 55.2 & 1.61 & 1.44 & 3.06 & 9.07 & 2.4951 & 1.7863 & 4.2814 \\
\hline D10S1643 & 74.5 & 55.27 & 2.57 & -0.25 & 2.32 & 12.535 & 2.4749 & 1.7821 & 4.2571 \\
\hline D10S1788 & 75.57 & 58.00 & 2.15 & 1.15 & 3.3 & & & & \\
\hline D10S464 & 79.03 & 61.26 & 0.82 & -0.31 & 0.51 & & & & \\
\hline D10S589 & 79.03 & 61.46 & 0.76 & 1.74 & 2.5 & & & & \\
\hline D10S609 & 80.19 & 63.76 & 0.83 & 1.05 & 1.89 & & & & \\
\hline D10S1225 & 80.77 & 64.75 & -0.27 & 1.74 & 1.47 & & & & \\
\hline D10S581 & 82.5 & 65.84 & 1.98 & 1.15 & 3.13 & & & & \\
\hline D10S1743 & 82.5 & 67.43 & 2.27 & 1.2 & 3.48 & 16 & 2.4635 & 1.7863 & 4.2499 \\
\hline D10S522 & 84.36 & 68.86 & 0.55 & 0.46 & 1.01 & 17.85 & 2.4564 & 1.7851 & 4.2415 \\
\hline D10S1670 & 86.2 & 68.87 & 2.24 & 1.74 & 3.98 & 19.7 & 2.4517 & 1.7863 & 4.238 \\
\hline D10S210 & 86.81 & 70.04 & 1.98 & 0.82 & 2.8 & 22.165 & 2.4297 & 1.7598 & 4.1878 \\
\hline $\mathrm{D} 10 \mathrm{~S} 2480$ & 86.81 & 70.32 & -0.39 & 1.74 & 1.35 & & & & \\
\hline D10S1672 & 89.21 & 71.02 & 1.58 & 1.15 & 2.73 & & & & \\
\hline D10S529 & 91.13 & 71.83 & 2.28 & 0.45 & 2.74 & 24.63 & 2.4124 & 1.7371 & 4.1463 \\
\hline \multirow[t]{2}{*}{ D10S537 } & 91.13 & 72.40 & 1.54 & 1.07 & 2.61 & 29.63 & 2.2272 & 1.5714 & 3.7956 \\
\hline & & & & & & 34.63 & 2.0503 & 1.4147 & 3.4622 \\
\hline
\end{tabular}

Markers in italics were used in haplotypes (Figure 1). Bold indicates markers at which maximum values were obtained in each analysis. Markers highlighted in gray are those that were selected for multipoint analysis in C, based on the results of single-marker analyses in B. In C, genetic distances from D10S604 are those generated from the multipoint analyses. 
The observed linkage scores were compared to the hypothetical maximum singlemarker scores obtained from these two families using simulation, assuming that the single marker has $80 \%$ heterozygosity (because the heterozygosity is not $100 \%$, the observed scores can exceed the simulated scores). SLINK (Ott, 1989) generated maximum simulated LOD scores of 2.58 and 1.74 for BRPD47 and BRPD50, respectively, and a score of 4.32 for the families combined. These are close to the maximum linkage scores we observed, suggesting that our linkage results explain all of the observed segregation of stuttering in these two families.

The haplotypes observed across the 20 microsatellite markers that showed evidence of linkage are presented in Figure 1. In family BRPD47, the haplotypes for individual 47 20 were inferred, as this individual was not available for study. Designation of this individual as affected is based on family report, which if correct, indicates that this individual stuttered without carrying the haplotype associated with stuttering in other family members. The haplotypes that segregate with stuttering differ in these two families. Although our haplotype results are consistent with our linkage findings in this region in both families, they suggest that these families do not share a mutation of common origin at this locus.
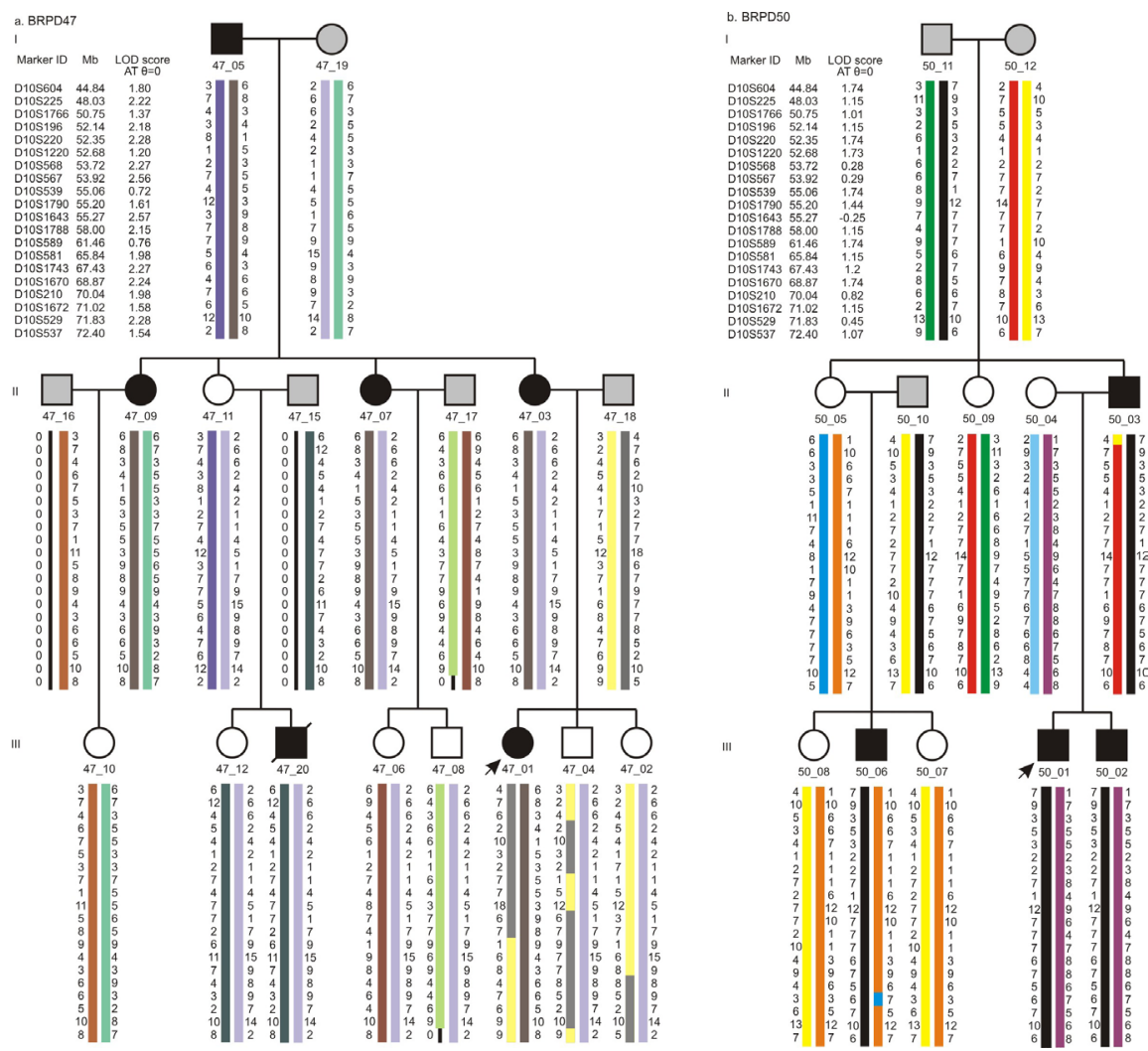

Figure 1. Pedigree of Brazilian families: a. BRPD47; b. BRPD50. Filled symbols in black represent affected individuals. Haplotypes of individuals in gray were estimated by MERLIN. The physical position in hg18/build 36 and estimated LOD score at $\theta=0$ for each marker are shown. The disease-associated haplotype is shown in dark brown in family BRPD47 and in black in family BRPD50. Individual 47 20 in BRPD47 was deceased at the time of ascertainment of the family. He was designated as affected based on family report, and his haplotypes are inferred. 


\section{DISCUSSION}

While persistent stuttering has failed to demonstrate a clear mode of inheritance in families in a number of previous studies, transmission of the disorder is consistent with autosomal dominant, perhaps with reduced penetrance, in two Brazilian families in our study. Linkage analysis under this model of inheritance generated highly significant evidence for linkage on chromosome 10q, with a combined multipoint LOD score of 4.28. Although our evidence for linkage came from only 2 of the 43 families in our sample, we note that the majority of the remaining families were small and showed low power to detect linkage individually. Our observation of linkage in a subset of families is also consistent with previous results that have demonstrated a high degree of heterogeneity among mapped loci for this disorder (Shugart et al., 2004; Riaz et al., 2005; Suresh et al., 2006; Kang et al., 2010; Raza et al., 2010, 2012). Thus, it is not surprising that our study found evidence of linkage in only a subset of the families, and that the linkage locus we identified in the Brazilian population has not been previously observed for stuttering.

One individual (individual 47_20 in family BRPD47) was designated as affected by family report and this individual's haplotypes were inferred, as he was not available for this study. If the diagnosis and haplotypes for this individual are correct, he represents a phenocopy because he stuttered but did not carry the disease-associated haplotype in this family. Such phenocopies have been observed in previous studies of large stuttering families (Kang et al., 2010). Such individuals indicate that even when a significant linkage score can be obtained under a Mendelian model of inheritance, stuttering can display non-Mendelian features.

The Brazilian population is characterized by a high degree of admixture. Genetic studies in such populations can use different genotypes and haplotypes that derive from the different racial or ethnic ancestral groups to improve the power to identify and localize disease-causing alleles. For this reason the Brazilian population is considered a valuable resource for mapping complex disease traits (Giolo et al., 2012). Previous studies in other populations, especially those containing consanguineous families have typically produced strongest evidence for linkage under a recessive model. In contrast, the families in our sample have no evidence of consanguinity and demonstrate linkage under a dominant model of inheritance, with evidence for different mutations at the same locus. This suggests that these families displaying linkage to chromosome 10q provide an opportunity to identify novel genetic mechanisms that underlie this disorder.

\section{CONCLUSION}

Our genome-wide linkage scan in the Brazilian population identified linkage in two families to chromosome 10q21 under dominant inheritance, which represents a novel locus and a novel mode of inheritance for this disorder.

\section{ACKNOWLEDGMENTS}

Research supported by the National Institute on Deafness and Other Communication Disorders/National Institutes of Health Intramural (Grant \#Z01-000046-12), and by the Coordination for the Improvement of Higher Education Personnel (CAPES) foundation, Brazil 
(C.E.F. Domingues). We thank M. Hashim Raza, Eduardo Sainz, Alejandro Schaffer, Thomas Friedman, and Andrew Griffith for technical guidance and comments on the manuscript, and the family members who participated in this research study.

\section{Conflicts of interest}

The authors declare no conflict of interest.

\section{REFERENCES}

Abecasis GR, Cherny SS, Cookson WO and Cardon LR (2002). Merlin - rapid analysis of dense genetic maps using sparse gene flow trees. Nat. Genet. 30: 97-101.

Alm PA and Risberg J (2007). Stuttering in adults: the acoustic startle response, temperamental traits, and biological factors. J. Commun. Disord. 40: 1-41.

Andrade CRF, Befi-Lopes DM, Fernandes FDM and Wertzner HF (2004). ABFW: Teste de Linguagem Infantil nas areas de Fonologia, Vocabulário, Fluência e Pragmática - $2^{\mathrm{a}}$ edn. Pro-Fono, Barueri.

Andrews G, Morris-Yates A, Howie P and Martin NG (1991). Genetic factors in stuttering confirmed. Arch. Gen. Psychiatry 48: 1034-1035.

Cottingham RW Jr, Idury RM and Schaffer AA (1993). Faster sequential genetic linkage computations. Am. J. Hum. Genet. 53: 252-263.

Cox NJ, Kramer PL and Kidd KK (1984). Segregation analyses of stuttering. Genet. Epidemiol. 1: 245-253.

Dworzynski K, Remington A, Rijsdijk F, Howell P, et al. (2007). Genetic etiology in cases of recovered and persistent stuttering in an unselected, longitudinal sample of young twins. Am. J. Speech Lang Pathol. 16: 169-178.

Fagnani C, Fibiger S, Skytthe A and Hjelmborg JV (2011). Heritability and environmental effects for self-reported periods with stuttering: a twin study from Denmark. Logoped. Phoniatr. Vocol. 36: 114-120.

Felsenfeld S, Kirk KM, Zhu G, Statham DJ, et al. (2000). A study of the genetic and environmental etiology of stuttering in a selected twin sample. Behav. Genet. 30: 359-366.

Fishelson M and Geiger D (2002). Exact genetic linkage computations for general pedigrees. Bioinformatics 18 (Suppl 1): S189-S198.

Giolo SR, Soler JM, Greenway SC, Almeida MA, et al. (2012). Brazilian urban population genetic structure reveals a high degree of admixture. Eur. J. Hum. Genet. 20: 111-116.

Hoffmann K and Lindner TH (2005). easyLINKAGE-Plus-automated linkage analyses using large-scale SNP data. Bioinformatics 21: 3565-3567.

Howie PM (1981). Concordance for stuttering in monozygotic and dizygotic twin pairs. J. Speech Hear. Res. 24: 317-321.

Kang C, Riazuddin S, Mundorff J, Krasnewich D, et al. (2010). Mutations in the lysosomal enzyme-targeting pathway and persistent stuttering. N. Engl. J. Med. 362: 677-685.

Kidd KK, Kidd J and Records MA (1978). The possible causes of the sex ratio in stuttering and its implications. J. Fluency Disord. 3: 13-23.

Ooki S (2005). Genetic and environmental influences on the handedness and footedness in Japanese twin children. Twin Res. Hum. Genet. 8: 649-656.

Ott J (1989). Computer-simulation methods in human linkage analysis. Proc. Natl. Acad. Sci. U. S. A. 86: 4175-4178.

Rautakoski P, Hannus T, Simberg S, Sandnabba NK, et al. (2012). Genetic and environmental effects on stuttering: a twin study from Finland. J. Fluency Disord. 37: 202-210.

Raza MH, Riazuddin S and Drayna D (2010). Identification of an autosomal recessive stuttering locus on chromosome 3q13.2-3q13.33. Hum. Genet. 128: 461-463.

Raza MH, Amjad R, Riazuddin S and Drayna D (2012). Studies in a consanguineous family reveal a novel locus for stuttering on chromosome 16q. Hum. Genet. 131: 311-313.

Riaz N, Steinberg S, Ahmad J, Pluzhnikov A, et al. (2005). Genomewide significant linkage to stuttering on chromosome 12. Am. J. Hum. Genet. 76: 647-651.

Riley GD (1994). A stuttering severity instrument for children and adults - 3rd edn. (SSI-3). Pro-Ed., Austin.

Seider RA, Gladstien KL and Kidd KK (1983). Recovery and persistence of stuttering among relatives of stutterers. $J$. Speech Hear. Disord. 48: 402-409.

Shugart YY, Mundorff J, Kilshaw J, Doheny K, et al. (2004). Results of a genome-wide linkage scan for stuttering. Am. 
J. Med. Genet. A 124A: 133-135.

Silberstein M, Tzemach A, Dovgolevsky N, Fishelson M, et al. (2006). Online system for faster multipoint linkage analysis via parallel execution on thousands of personal computers. Am. J. Hum. Genet. 78: 922-935.

Suresh R, Ambrose N, Roe C, Pluzhnikov A, et al. (2006). New complexities in the genetics of stuttering: significant sexspecific linkage signals. Am. J. Hum. Genet. 78: 554-563.

Thiele H and Nurnberg P (2005). HaploPainter: a tool for drawing pedigrees with complex haplotypes. Bioinformatics 21: $1730-1732$.

Viswanath N, Lee HS and Chakraborty R (2004). Evidence for a major gene influence on persistent developmental stuttering. Hum. Biol. 76: 401-412. 